\title{
Association of hypertension and dyslipidaemia with increasing obesity in patients with Type 2 Diabetes Mellitus
}

\author{
Zikria Saleem¹, Hamid Saeed*1, Zohaib Abbas Khan², Muhammad Imran Hassan Khan³, Furqan \\ Khurshid Hashmi', Muhammad Islam', Afzaal Bashir ${ }^{4}$, Saleha Sadeeqa ${ }^{5}$
}

${ }^{1}$ Department of Clinical Pharmacy, University College of Pharmacy, University of the Punjab, Allama Iqbal Campus, 54000, Lahore, Pakistan, ${ }^{2}$ Department of Pharmacology, University College of Pharmacy, University of the Punjab, Allama Iqbal Campus, 54000, Lahore, Pakistan, ${ }^{3}$ Diabetes, Endocrine and Metabolic Centre (DEMC), Lahore General Hospital, Lahore, Pakistan, ${ }^{4}$ King Edward Medical University (KEMU), Lahore, Pakistan, ${ }^{5}$ Institute of Pharmacy, Lahore College for Women University, Jail Road, Lahore, Pakistan

\begin{abstract}
The study was performed to estimate the association of hypertension and dyslipidaemia with increasing body weight and obesity in Type II diabetics of Lahore, Pakistan. An observational study was conducted by enrolling 2708 obese diabetics from four diabetes care centres of Lahore, Pakistan. Data was collected for a period of 7 months. Associations were estimated using chi-square, binary and multinomial logistic regression. Data suggested that blood pressure, systolic and diastolic, exhibited continual increase with increasing body weight and obesity class in diabetes patients with $41.8 \%$ increase in the prevalence of hypertension in obesity class III subjects (OR; 1.91, p=0.02). Likewise, triglycerides and total cholesterol exhibited continual increase in their mean values with increasing obesity, i-e., an overall increase in the prevalence of dyslipidaemia of $27.2 \%$ in obesity class 3 subjects (OR; 1.94, $p=0.29)$. Taken together, this data suggested that hypertension is potentially associated with increasing obesity in diabetics, while dyslipidaemia demonstrated plausible association only with obesity class 3 .
\end{abstract}

Keywords: Type II Diabetes Mellitus. Dyslipidaemia. Obesity. HbA1c. Lahore/Pakistan.

\section{INTRODUCTION}

Despite recent advancements in diabetes research, the worldwide prevalence of diabetes continues to grow, i-e., $2.8 \%$ in 2000 and is estimated to be $\sim 4.4 \%$ in 2030 with projected increase from 171 million in 2000 to above 350 million in 2030 (Wild et al., 2004). Besides, diabetes has been associated with higher incidence of hospitalization, blindness, renal failure and nontraumatic amputation, majorly contributing towards escalating healthcare costs (Rubin, Altman, Mendelson, 1994). According to World Health Organization (WHO) estimates, the global number of diabetics will likely to double over the next 25 years and during this period, the larger burden of the disease will be shared by developing nations - particularly South Asian countries (Amos,

\footnotetext{
*Correspondence: H. Saeed. Department of Clinical Pharmacy, University College of Pharmacy, University of the Punjab, Allama Iqbal Campus, 54000, Lahore, Pakistan University College of Pharmacy, University of the Punjab. Tel.: 0092-304-880-1243. E-mail: hamid.pharmacy@pu.edu.pk
}

McCarty, Zimmet, 1997). Pakistan belongs to a high prevalence area, ranked $7^{\text {th }}$ globally, having 6.9 million people in 2010 and is expected to double in 2025 affecting 11.9 million people (Qidwai, Ashfaq, 2010; Whiting et al., 2011).

Numerous literature evidences suggest that hypertension and obesity increase the risk of long term vascular complications and these risks become more detrimental due to limited access to health care and inadequate prevention of concomitant diseases, such as chronic kidney disease, stroke, peripheral vascular disease and heart disease (Colosia, Palencia, Khan, 2013). Additionally, the relative risk of developing cardiovascular diseases in diabetics is more than double compared to nondiabetics counterparts. Besides, in developing countries limited access and inadequate prevention strategies further aggravate the debilitating complications in diabetics (Kennel, McGee, 1979; Yusuf et al., 2001). Studies have also shown that optimal blood pressure control and within range lipid profiles confer cardiovascular benefits 
in patients with type II diabetes (AdLer et al., 2000; LeRoith, 2008) - a reduction in $10 \mathrm{mmHg}$ systolic blood pressure was associated with risk reduction of $12 \%$ in diabetic complications, $15 \%$ in diabetes related deaths, $11 \%$ in myocardial infarction and $13 \%$ in microvascular complications (AdLer et al., 2000; LeRoith, 2008). Likewise, reduction in the levels of low-density lipoprotein cholesterol (LDL-C) resulted in lower incidence of major coronary artery risks in diabetics (Berry, Tardif, Bourassa, 2007). Seemingly, obesity acts as an insidious player in the patho-physiology of hypertension and diabetes, hence clustering of risk factors seems to have a greater impact on worse disease outcomes rather than individual risk factors (Song, Hardisty, 2008). Notably, abdominal obesity in diabetics along with multifactorial pathophysiology of dyslipidemia leads to augmented risk of mortality for coronary artery disease (Carr, Brunzell, 2004; Franssen et al., 2011; Yoshino, Hirano, Kazumi, 1996). NHANES studies (1999 to 2004) showed that patients with obesity have double chances of developing dyslipidaemia than those with normal weight (Yoshino, Hirano, Kazumi, 1996). Thus, metabolic syndrome, such as diabetes with concomitant presence of hypertension, dyslipidaemia, pro-inflammatory and prothrombic states can contribute towards complex pathological conditions involving multiple pathways (LeRoith, 2008). Yet, a very few literature evidences exist that evaluated the association of hypertension and dyslipidaemia in obese diabetics not a single study from Pakistan. Thus, the present study, the first study, was aimed at examining the association of hypertension, dyslipidaemia with obesity in diabetics of Lahore, Pakistan.

\section{METHODS}

\section{Ethical approval}

Ethical approval for the study was obtained from the human ethics committee, University College of Pharmacy, University of the Punjab, reference \#; EC/UCP/122/2015. All the procedures were in accordance with the principles of the declaration of Helsinki 1975 and its ensuing amendments (Association WM, 2009).

\section{Study design}

An observational study from December 2015 to June 2016, 7 months, was conducted by enrolling 2708 patients from tertiary care public hospitals of Lahore, Pakistan. Diabetics were identified from the hospital health information system as per clinician's confirmed diagnosis.
All the necessary data, as per study objectives, were retrieved from patient's medical profiles made accessible upon approval of the study from hospital administration. Data was obtained from Lahore General Hospital (LGH), Mayo Hospital Lahore, Diabetes Management Centre (DMC) and Services Hospital Lahore. Patient's data was then segregated according to body mass index (BMI, kg/ $\mathrm{m}^{2}$ ) described below;

\section{Obesity}

Degree of obesity was categorized as per National Heart, Lung and Blood Institute's definition for overweight and obesity (Initiative NOE et al., 2002). Body mass index (BMI, $\mathrm{kg} / \mathrm{m}^{2}$ ) was calculated using the formula given below:

$$
B M I=w t(k g) / h^{2}(m)
$$

BMI based weight categories include, underweight; $<18.5 \mathrm{~kg} / \mathrm{m}^{2}$, normal weight; $18.5-24.9 \mathrm{~kg} / \mathrm{m}^{2}$ and overweight; $25-29.9 \mathrm{~kg} / \mathrm{m}^{2}$. Obesity was classified into three classes; Obesity class I; $30-34.9 \mathrm{~kg} / \mathrm{m}^{2}$, Obesity class II; $35-39.9 \mathrm{~kg} / \mathrm{m}^{2}$ and Obesity class III; $>40 \mathrm{~kg} / \mathrm{m}^{2}$.

\section{STUDY POPULATION}

Potential subjects were identified from hospitals databases and included in the study as per approved inclusion and exclusion criteria.

Inclusion Criteria: All uncontrolled diabetics, HbAlc above $7 \%$, irrespective of gender, ethnicity and area of residence, above 25 years of age, sans any chronic kidney disease or mental health issues were included in the study. All the participants must have a disease (diabetes) duration of more than 5 years at the time of enrolment and were visiting the hospitals from December 2015 to June 2016.

Exclusion criteria: all controlled diabetic patients, below 25 years of age, having impaired cognition and had a disease duration of less than 5 years were excluded from the study.

\section{Study endpoints}

Following endpoints were considered as per standard guidelines;

\section{Diabetes Mellitus (DM)}

Patients having diabetes (type II) were identified from hospital medical records as per physician's 
evaluation of successive blood glucose tests, i-e., patient's having fasting glucose $>125 \mathrm{mg} / \mathrm{dL}$, having HbA1c levels $>7 \%$. DM was defined according to the levels of $\mathrm{HbA} 1 \mathrm{c}$ as defined by American Diabetes Association (ADA) Guidelines 2015. HbA1c levels of $<7 \%$ and $>$ $7 \%$ were considered controlled and uncontrolled diabetes, respectively (Association $\mathrm{AD}, 2015)$.

\section{Hypertension}

Participants were considered hypertensive if their systolic and diastolic blood pressure was $>140$ and 90 $\mathrm{mmHg}$, respectively. Hypertensive patients were classified according to Seventh Report of the Joint National Committee on Prevention, Detection, Evaluation, and Treatment of High Blood Pressure (JNC 7) (Chobanian et al., 2003). The classification was as follows; Normal; Systolic Blood Pressure (SBP) $<120 \mathrm{mmHg}$ and Diastolic Blood Pressure (DBP) $<80 \mathrm{mmHg}$, prehypertension; SBP 120-139 mmHg and DBP 80-89 $\mathrm{mmHg}$, Stage I hypertension; SBP 140-159 mmHg and DBP 90 - 99 $\mathrm{mmHg}$ and Stage II hypertension; SBP is $>160 \mathrm{~mm}$ of $\mathrm{Hg}$ and $\mathrm{DBP}>100 \mathrm{~mm}$ of $\mathrm{Hg}$.

\section{Dyslipidemia}

Patients were considered dyslipidemic based on elevated cholesterol or serum triglycerides levels. A total cholesterol (TC) level $>200 \mathrm{mg} / \mathrm{dL}$ or triglyceride (TG) level $>150 \mathrm{mg} / \mathrm{dL}$ was considered as abnormal ${ }^{21}$. Similarly, low density lipoproteins (LDL) $>100 \mathrm{mg} / \mathrm{dL}$ or high density lipoproteins (HDL) $<40 \mathrm{mg} / \mathrm{dL}$ in men and $<50 \mathrm{mg} / \mathrm{dL}$ in women were considered for dyslipidaemia.

\section{Data analysis}

Data were analyzed using IBM SPSS 22. Crosstabulation was performed to assess the percentages of different variables with body mass index. Chi-square test was used to estimate the association of demogrpahic variables and to examine the proportions of disease prevalence with respect to obesity class. Multivariate logistic regression analysis was performed to assess the association of obesity class, odds ratios (with normal weight as the reference point), with hypertension and dyslipidemia. An alpha value of less than 0.05 was considered statistically significant.

\section{RESULTS}

From December 2015 to June 2016, a total of 2708 eligible diabetics were enrolled, out of which $62 \%$ were male and $38 \%$ were female.

\section{Patient's basic demographics}

Patient's basic demographics are summarized in Table I. As per obesity class groups, most of the subjects belonged to overweight category $(37.1 \%)$ followed by normal weight $(27.4 \%)$, obesity class I $(22.7 \%)$, obesity class II (7.6\%) and obesity class III (2.1\%) (Table I). Maximum number of patients, 1036 (38.3\%), were within 46 - 55 years of age with major contribution from overweight category (39.4\%) followed by normal weight population $(27.4 \%)$. Out of total enrolments, $62 \%$ were males and $38 \%$ were females, yet exhibited equal frequency distribution in majority of obesity class categories (Table I). Likewise, population frequency distribution for smoking status and neuropathy were almost similar for the obesity classes, when estimated for their presence (YES) or absence (NO) (Table I).

Prevalence of neuropathy in enrolled population was $26.9 \%$ in normal weight class and $36.9 \%$ in over weight class, while only $23.1 \%$ in obesity class I, $7.9 \%$ in obesity class II and $2.1 \%$ in obesity class III developed this complication (Table I).

\section{Patient's clinical characteristics}

Next we examined the clinical characteristics of our study population - summarized in Table II. As shown in Table II, blood pressure profiles, systolic (SBP) and diastolic (DBP), demonstrated steady increase with increase in obesity. Similarly, triglycerides and cholesterol exhibited continual increase in their mean values with increase in obesity - a clear manifestation in obesity class III subjects having extremely higher mean values for triglycerides (206.9 \pm 96.6$)$ and cholesterol $(244 \pm 45.5)$ (Table II). Moreover, HDL mean values were also higher in population residing in normal weight and obese class I categories, while LDL was found higher in obese class III subjects (Table II).

\section{Frequency distribution of hypertension stages and un-controlled lipid profiles among obesity classes}

As shown in Table III, more than $65 \%$ of normotensive patients, $29.8 \%$ of the total, were either in normal body weight category $(33.2 \%)$ or in over weight category $(34.3 \%)$. On the other hand, based on hypertension stages, as for overweight plus obesity class I categories, more than $50 \%$ of the patients with pre-hypertensive stage, stage I and II were representing either in over weight (Pre-HTN: $37.9 \%$, Stage-I: 38.3\%, Stage-II: $38.1 \%$ ) or in obesity class I category (Pre-HTN: 
TABLE I - Patient's basic demographics

\begin{tabular}{|c|c|c|c|c|c|c|c|}
\hline \multirow{4}{*}{ Characteristics } & & \multicolumn{6}{|c|}{ Obesity Class (Body Mass Index, kg/m²) } \\
\hline & & $\begin{array}{l}\text { Under } \\
\text { Weight }\end{array}$ & $\begin{array}{l}\text { Normal } \\
\text { Weight }\end{array}$ & $\begin{array}{c}\text { Over } \\
\text { Weight }\end{array}$ & $\begin{array}{l}\text { Obesity } \\
\text { Class } 1\end{array}$ & $\begin{array}{l}\text { Obesity } \\
\text { Class II }\end{array}$ & $\begin{array}{l}\text { Obesity } \\
\text { Class III }\end{array}$ \\
\hline & & $(<18.5)$ & $(18.5-24.9)$ & $(25-29.9)$ & $(30-34.9)$ & $(35-39.9)$ & $(>40)$ \\
\hline & $\begin{array}{c}\text { Total } \\
\boldsymbol{n}=2708\end{array}$ & $\begin{array}{c}n=82 \\
3 \%)\end{array}$ & $\begin{array}{c}n=743 \\
(27.4 \%)\end{array}$ & $\begin{array}{l}n=1005 \\
(37.1 \%)\end{array}$ & $\begin{array}{c}n=615 \\
(22.7 \%)\end{array}$ & $\begin{array}{l}n=206 \\
(7.6 \%)\end{array}$ & $\begin{array}{c}n=57 \\
(2.1 \%)\end{array}$ \\
\hline \multicolumn{8}{|l|}{ Age (Years) } \\
\hline$<25$ & 50 & $13(26 \%)$ & $26(52 \%)$ & $8(16 \%)$ & $2(4 \%)$ & $0(0 \%)$ & $1(2 \%)$ \\
\hline $25-35$ & 178 & $13(7.3 \%)$ & $58(32.6 \%)$ & $54(30.3 \%)$ & $37(20.8 \%)$ & $15(8.4 \%)$ & $1(0.6 \%)$ \\
\hline $36-45$ & 668 & $15(2.3 \%)$ & $140(20.9 \%)$ & $248(37.1 \%)$ & $179(26.8 \%)$ & $70(10.5 \%)$ & $16(2.4 \%)$ \\
\hline $46-55$ & 1036 & $22(2.1 \%)$ & $285(27.5 \%)$ & $408(39.4 \%)$ & $218(21.1 \%)$ & $76(7.3 \%)$ & $27(2.6 \%)$ \\
\hline $56-65$ & 603 & $14(2.3 \%)$ & $174(28.9 \%)$ & $210(34.8 \%)$ & $155(5.7 \%)$ & $39(6.5 \%)$ & $11(1.8 \%)$ \\
\hline$>65$ & 173 & $5(2.9 \%)$ & $60(34.7 \%)$ & $77(44.5 \%)$ & $24(13.9 \%)$ & $6(3.5 \%)$ & $1(0.6 \%)$ \\
\hline \multicolumn{8}{|l|}{ Gender } \\
\hline Male & 1683 & $51(3 \%)$ & $455(27 \%)$ & $620(36.8 \%)$ & $391(23.2 \%)$ & $133(7.9 \%)$ & $33(1.9 \%)$ \\
\hline Female & 1025 & $31(3.1 \%)$ & $288(28.1 \%)$ & $385(36.6 \%)$ & $224(21.6 \%)$ & $73(7.1 \%)$ & $24(2.3 \%)$ \\
\hline \multicolumn{8}{|l|}{ Current Smoker } \\
\hline Yes & 498 & $17(3.4 \%)$ & $123(24.7 \%)$ & $176(35.4 \%)$ & $115(23.1 \%)$ & $59(11.8 \%)$ & $8(1.6 \%)$ \\
\hline No & 2210 & $65(2.9 \%)$ & $620(28.1 \%)$ & $829(37.5 \%)$ & $500(22.6 \%)$ & $147(6.7 \%)$ & $49(2.2 \%)$ \\
\hline \multicolumn{8}{|l|}{ Neuropathy } \\
\hline Yes & 1814 & $55(3.1 \%)$ & $487(26.9 \%)$ & $669(36.9 \%)$ & $422(23.3 \%)$ & $144(7.9 \%)$ & $37(2.1 \%)$ \\
\hline No & 894 & $27(3.1 \%)$ & $256(28.6 \%)$ & $336(37.6 \%)$ & $193(21.6 \%)$ & $62(6.9 \%)$ & $20(2.2 \%)$ \\
\hline
\end{tabular}

TABLE II - Blood pressure, HbA1c and lipid profiles as per body weight and obesity class

\begin{tabular}{|c|c|c|c|c|c|c|}
\hline \multirow{3}{*}{ Parameters } & \multicolumn{6}{|c|}{ Obesity Class (Body Mass Index, $\mathrm{kg} / \mathrm{m}^{2}$ ) } \\
\hline & $\begin{array}{c}\text { Under } \\
\text { Weight }\end{array}$ & $\begin{array}{l}\text { Normal } \\
\text { Weight } \\
\end{array}$ & $\begin{array}{c}\text { Over } \\
\text { Weight }\end{array}$ & $\begin{array}{c}\text { Obesity } \\
\text { Class I } \\
\end{array}$ & $\begin{array}{l}\text { Obesity } \\
\text { Class II } \\
\end{array}$ & $\begin{array}{c}\text { Obesity } \\
\text { Class III }\end{array}$ \\
\hline & $(<18.5)$ & $(18.5-24.9)$ & $(25-29.9)$ & $(30-34.9)$ & $(35-39.9)$ & $(>40)$ \\
\hline$\overline{\text { SBP }(\text { Mean } \pm \text { SD })}$ & $123.4 \pm 18.3$ & $131.3 \pm 19.7$ & $134.3 \pm 19.7$ & $135.4 \pm 19.7$ & $136.6 \pm 17.8$ & $142.1 \pm 28.4$ \\
\hline$\%$ increase & - & - & $2.3 \%$ & $3 \%$ & $4 \%$ & $8.2 \%$ \\
\hline DBP $($ Mean \pm SD $)$ & $81.5 \pm 13.4$ & $84.2 \pm 1.9$ & $86.2 \pm 12.3$ & $86.1 \pm 12.8$ & $86.7 \pm 11.1$ & $88.8 \pm 15$ \\
\hline$\%$ increase & - & - & $2.4 \%$ & $2.3 \%$ & $3 \%$ & $5.5 \%$ \\
\hline HbA1c (Mean \pm SD) & $8.1 \pm 1.8$ & $8.6 \pm 1.9$ & $8.4 \pm 1.8$ & $8.7 \pm 1.9$ & $8.3 \pm 1.6$ & $8.3 \pm 1.6$ \\
\hline$\%$ increase & - & - & $-2.3 \%$ & $1.16 \%$ & $-3.5 \%$ & $-3.5 \%$ \\
\hline HDL $($ Mean \pm SD) & $37.9 \pm 8.7$ & $42.5 \pm 15.8$ & $40.7 \pm 12.8$ & $42.1 \pm 14.3$ & $41 \pm 15.2$ & $41.1 \pm 13.6$ \\
\hline$\%$ increase & - & - & $-4.2 \%$ & $-0.9 \%$ & $-3.5 \%$ & $-3.5 \%$ \\
\hline LDL $($ Mean \pm SD) & $101.1 \pm 19.6$ & $108.1 \pm 26.4$ & $109.9 \pm 30.9$ & $112.2 \pm 33.5$ & $110.7 \pm 28.7$ & $113.2 \pm 28.1$ \\
\hline$\%$ increase & - & - & $1.7 \%$ & $3.79 \%$ & $2.4 \%$ & $4.7 \%$ \\
\hline Triglycerides (Mean $\pm \mathrm{SD}$ ) & $180.6 \pm 72.5$ & $181.6 \pm 61.9$ & $183.2 \pm 65.9$ & $182.7 \pm 65.8$ & $184.6 \pm 64.5$ & $206.9 \pm 96.6$ \\
\hline$\%$ increase & - & - & $0.9 \%$ & $0.6 \%$ & $1.65 \%$ & $14 \%$ \\
\hline Cholesterol (Mean \pm SD) & $210.1 \pm 42.9$ & $220.4 \pm 46.3$ & $216.6 \pm 49.9$ & $217 \pm 47.1$ & $224.2 \pm 50.4$ & $244 \pm 45.5$ \\
\hline$\%$ increase & - & - & $-1.7 \%$ & $-1.5 \%$ & $1.7 \%$ & $10.7 \%$ \\
\hline
\end{tabular}


22.7\%, Stage-I: $24.3 \%$, Stage-II: $25.8 \%$ ) (Table III). Out of total subjects (498) having positive smoking status, $223(44.8 \%)$ had hypertension and $110(22.1 \%)$ were found pre-hypertensive (Table III). As for lipid profiles, combining together obesity class I, class II and class III subjects, almost $40.7 \%$ subjects had uncontrolled total cholesterol (TC), 39.1\% with uncontrolled triglycerides (TG), 40.4\% with un-controlled low density lipoproteins (LDL) and $36.7 \%$ with un-controlled high density lipoproteins (HDL) (Table III).

\section{Prevalence of hypertension and dyslipidaemia in obese diabetics}

Furthermore, when percentage changes were estimated with regards to hypertension prevalence between normal weight and obesity class III population, the prevalence of hypertension increased significantly in obesity class III subjects (53.6\%), a percentage increase of $41.8 \%$, in comparison to normal weight population (37.8\%) (Table IV). When evaluated for gender; male population in obesity class III exhibited a percentage increase of $19.3 \%$ in the prevalence of hypertension compared to normal weight counterparts, while female population demonstrated a negative trend (Table IV). Moreover, population $\leq 45$ years of age in obese class III category demonstrated a significant increase in hypertension prevalence, i-e., an increase of 50\%, compared to normal weight subjects (Table IV). Similar trend was observed in smoking population of obese class III category, i-e., a percentage increase of $22.7 \%$ (Table IV).

Data further demonstrated that compared to normal weight subjects, obese class III subjects had 27.3\% increase in the prevalence of dyslipidaemia (Table IV). Additionally, unlike negative trend observed in female subjects in the prevalence of hypertension, female subjects in obesity class III category exhibited $27.2 \%$ increase in dyslipidaemia compared to normal weight subjects (Table IV). Conversely, males demonstrated a significant decrease in dyslipidaemia (57.8\%) prevalence with increasing obesity. Besides, we also observed an upward trend in the prevalence of dyslipidaemia when examined for smoking status $(20.94 \%)$ and in subjects $\leq 45$ years of age (14\%) (Table IV).

\section{Association of hypertension and dyslipidaemia with obesity in diabetics}

Finally, we aimed at estimating an association of different obesity classes with that of hypertension and dyslipidaemia. Data demonstrated significant association of hypertension with obesity classes, nonetheless, with higher propensity in obesity class III category (OR; 1.9, $p=0.02$ ) versus normal body weight subjects (Table V). Moreover, the chances of dyslipidaemia were found higher.

TABLE III - Hypertension stages and un-controlled lipid profiles according to patient's body weight and obesity class measurements

\begin{tabular}{|c|c|c|c|c|c|c|c|}
\hline \multirow[t]{3}{*}{ Characteristics } & & \multicolumn{6}{|c|}{ Obesity Class (Body Mass Index, kg/m²) } \\
\hline & & $\begin{array}{l}\text { Under } \\
\text { Weight }\end{array}$ & $\begin{array}{l}\text { Normal } \\
\text { Weight }\end{array}$ & $\begin{array}{c}\text { Over } \\
\text { Weight }\end{array}$ & $\begin{array}{c}\text { Obesity } \\
\text { Class I }\end{array}$ & $\begin{array}{l}\text { Obesity } \\
\text { Class II }\end{array}$ & $\begin{array}{c}\text { Obesity } \\
\text { Class III }\end{array}$ \\
\hline & & $(<18.5)$ & $(18.5-24.9)$ & $(25-29.9)$ & $(30-34.9)$ & $(35-39.9)$ & $(>40)$ \\
\hline Normal & $\begin{array}{c}\text { Total } \\
n=808\end{array}$ & $42(5.2 \%)$ & $268(33.2 \%)$ & $277(34.3 \%)$ & $161(19.2 \%)$ & $45(5.7 \%)$ & $15(1.9 \%)$ \\
\hline Prehypertension & 686 & $20(2.9 \%)$ & $177(25.8 \%)$ & $260(37.9 \%)$ & $156(22.7 \%)$ & $62(9.1 \%)$ & $11(1.6 \%)$ \\
\hline HTN Stage1 & 786 & $15(1.9 \%)$ & $193(24.6 \%)$ & $301(38.3 \%)$ & $191(24.3 \%)$ & $71(9.1 \%)$ & $15(1.9 \%)$ \\
\hline HTN Stage2 & 341 & $4(1.2 \%)$ & $77(22.6 \%)$ & $130(38.1 \%)$ & $88(25.8 \%)$ & $27(7.9 \%)$ & $15(4.4 \%)$ \\
\hline \multicolumn{8}{|c|}{ Un-controlled Lipid Profiles } \\
\hline $\mathbf{T C}(>200 \mathrm{mg} / \mathrm{dL})$ & 901 & $29(3.2 \%)$ & $211(23.4 \%)$ & $294(32.6 \%)$ & $248(27.5 \%)$ & $94(10.4 \%)$ & $25(2.8 \%)$ \\
\hline TG $(>150 \mathrm{mg} / \mathrm{dL})$ & 996 & $28(2.8 \%)$ & $245(24.6 \%)$ & $334(33.5 \%)$ & $265(26.6 \%)$ & $99(9.9 \%)$ & $25(2.5 \%)$ \\
\hline $\mathbf{L D L}(>100 \mathrm{mg} / \mathrm{dL})$ & 755 & $19(2.6 \%)$ & $168(22.9 \%)$ & 25134.1 & $203(27.6 \%)$ & $74(10.1 \%)$ & $20(2.7 \%)$ \\
\hline $\begin{array}{l}\text { HDL } \\
(\text { men; }>40 \mathrm{mg} / \mathrm{dL}), \\
\text { women }(>50 \mathrm{mg} / \mathrm{dL})\end{array}$ & 611 & $19(3.1 \%)$ & $149(24.4 \%)$ & $219(35.8 \%)$ & $145(23.7 \%)$ & $62(10.1 \%)$ & $17(2.8 \%)$ \\
\hline
\end{tabular}

Abbreviations: Normal; SBP < 120 mmHg, DBP 80 mmHg, Prehypertension; SBP 120-139 mmHg, DBP 80-89 mmHg, HTN Stage 1; SBP 140-159 mmHg, DBP 90 - 99 mmHg, HTN Stage2; SBP > 160mm of Hg , DBP > 100mm of Hg, TC; Total Cholesterol, TG; triglycerides, LDL; low density lipoproteins, HDL; high density lipoproteins 
TABLE IV - Changes in hypertension \& dyslipidaemia prevalence by obesity class

\begin{tabular}{|c|c|c|c|}
\hline \multirow{2}{*}{ Parameters } & \multicolumn{3}{|c|}{ Changes in Hypertension Prevalence } \\
\hline & Normal (\%) & Obese Class III (\%) & \% Increase/Decrease \\
\hline Total & 37.8 & 53.6 & 41.80 \\
\hline \multicolumn{4}{|l|}{ Gender } \\
\hline Male & 41.90 & 50 & 19.30 \\
\hline Female & 58.10 & 50 & -13.90 \\
\hline \multicolumn{4}{|l|}{ Age } \\
\hline$\leq 45$ & 17.80 & 26.70 & 50 \\
\hline$>45$ & 82.20 & 73.30 & -10.80 \\
\hline Smoking & 16.30 & 20 & 22.70 \\
\hline \multirow[t]{3}{*}{ Neuropathy } & 65.5 & 64.90 & -0.92 \\
\hline & \multicolumn{3}{|c|}{ Changes in Dyslipidaemia Prevalence } \\
\hline & Normal (\%) & Obese Class III (\%) & \% Increase/Decrease \\
\hline Total & 40 & 54.9 & 27.20 \\
\hline \multicolumn{4}{|l|}{ Gender } \\
\hline Male & 50.50 & 32 & -57.80 \\
\hline Female & 49.50 & 68 & 27.20 \\
\hline \multicolumn{4}{|l|}{ Age } \\
\hline$\leq 45$ & 33.30 & 38.70 & 14 \\
\hline$>45$ & 66.67 & 61.30 & -8.80 \\
\hline Smoking & 12.65 & 16 & 20.94 \\
\hline Neuropathy & 72.70 & 77.50 & 6.20 \\
\hline
\end{tabular}

\section{DISCUSSION}

Numerous literature reports suggest that hypertension, dyslipidaemia and diabetes are common conditions associated with obesity (Anari et al., 2017; Nguyen et al., 2008). In our data we found overt representation of diabetics in overweight category, mostly males, between $46-55$ years of age, demonstrating continual increase in mean hypertension and cholesterol values with increasing obesity. Moreover, obese class III population exhibited percentage increases, compared to normal weight population, in the prevalence of hypertension and dyslipidaemia, yet with variations with regards to age and gender. Likewise, hypertension

TABLE V - Multivariate logistic regression - Odds of hypertension and dyslipidaemia prevalence with increasing obesity class

\begin{tabular}{lcccccc}
\hline \multicolumn{7}{c}{ Multivariate Logistic Regression } \\
\hline Weight \& & \multicolumn{5}{c}{ Hypertension } & \multicolumn{3}{c}{ Dyslipidaemia } \\
\cline { 2 - 7 } Obesity Class & OR & $\mathbf{9 5 \%}$ CI & p-value & OR & $\mathbf{9 5 \%}$ CI & p-value \\
\hline Normal & 1 (Reference) & & 1 (Reference) & & \\
Under Weight & 0.51 & $0.30-0.86$ & $0.012^{*}$ & 0.8 & $0.36-1.75$ & 0.56 \\
Overweight & 1.32 & $1.09-1.61$ & $0.005^{* *}$ & 0.75 & $0.52-1.07$ & 0.11 \\
Obese Class I & 1.45 & $1.16-1.81$ & $0.001^{* *}$ & 0.89 & $0.61-1.32$ & 0.57 \\
Obese Class II & 1.51 & $1.10-2.01$ & $0.01^{*}$ & 1.11 & $0.64-1.92$ & 0.71 \\
Obese Class III & 1.91 & $1.10-3.29$ & $0.02^{*}$ & 1.94 & $0.57-6.59$ & 0.29 \\
\hline
\end{tabular}

$*$ p $0.05-<0.01, * * \mathrm{p}<0.01-0.0005$ 
exhibited strong association with obesity as demonstrated by significant increase in hypertension with increasing obesity - maximum in obesity class III. Similar trends were observed for dyslipidaemia, i-e., higher likelihood of dyslipidaemia with increasing obesity, yet the association was not statistically significant.

According to literature reports, obesity can contribute towards hypertension, dyslipidaemia and hyperglycaemia, thus can modulate cardiovascular disease (CVD) risks (LeRoith, 2008). In this regard, HbA1c, triglycerides, total cholesterol and blood pressure, SBP \& DBP, has been shown to associate significantly with obesity in diabetics of Indian origin (Prabodh et al., 2012). Interestingly, similar to the above mentioned observations, in our population of Indian sub-continent, i-e., in Pakistan, we observed linear increase in most of the biological factors, such as SBP, DBP, triglycerides and total cholesterol with increase in obesity class - demonstrating maximum mean values in patients representing obesity class III. Several literature evidences suggest that most of diabetics, irrespective of gender, having hypertension, dyslipidaemia and obesity were frequently reported in patients above 50 years of age (Anari et al., 2016). Our data corroborated the above mentioned findings, however, when ascertained for percentage changes, from normal body weight to obesity class III, in the prevalence of hypertension, diabetes and dyslipidaemia, subjects between $30-45$ years of age exhibited maximum percentage increases, i-e., higher prevalence of these diseases with increasing obesity. We also, observed that most of our enrolled patients had neuropathy, this higher frequency might be attributed to higher $\mathrm{HbA} 1 \mathrm{c}$ values rather than obesity per se, since we did not observe an increasing trend with increase in obesity class in patients with neuropathy. Seemingly, obesity alone is not linked to neuropathy rather a risk factor in obese diabetics, which can aggravate neuropathic pain due to obesity associated inflammation (Hozumi et al., 2016).

Numerous literature evidences suggest that hypertension and diabetes are strongly associated with body weight and obesity (Nguyen et al., 2008; Patel et al., 2016). A study conducted in Spain showed that diabetics having obesity are more prone to develop hypertension and dyslipidaemia - 92.6\% patients had dyslipidaemia and $73.7 \%$ had hypertension (Gomis et al., 2014). Likewise, it is reported that the prevalence of hypertension in western population increase with age and obesity, yet even adjusted for age and obesity, hypertension prevalence was still 1.5 times higher in diabetics (Turner et al., 1993). In this context, our data further substantiated this concept that hypertension is strongly associated with increasing body weight class in diabetics of Lahore Pakistan, exhibiting higher susceptibility of hypertension with increasing obesity. Studies also demonstrated that type II diabetes and hypertension are strongly associated with end organ damage, the retina and kidney, while the similar association is less evident for obesity and dyslipidaemia (Fong et al., 2004; Wong, Mitchell, 2004). These data and literature evidences suggested that hypertension along with diabetes are key players in augmenting diabetic complications and cardiovascular disease risks rather than obesity and dyslipidaemia, nonetheless, it is highly likely that co-existence of obesity and dyslipidemia might further aggravate the clinical condition.

Moreover, the association between diabetes and metabolic dysregulators, such as dyslipidemia and obesity have been reported previously (Sheth et al., 2015). In this regard, a strong association has been observed between $\mathrm{HbA1}$ c of diabetics (type II) and dyslipidemic obesity, with strong positive association of $\mathrm{HbA} 1 \mathrm{c}$ with triglycerides and cholesterol (Prabodh et al., 2012; Sheth et al., 2015). Our data suggested that dyslipidemia prevalence was significantly increased in diabetics in obesity class III, predominantly in females and those having positive smoking status. These findings were further supported by association estimates suggesting that dyslipidemia was significantly higher in obesity class III diabetics in comparison to normal and over-weight subjects. Interestingly, when dyslipidemia prevalence was estimated with regards to gender, compared to males, females were demonstrating higher percentage increases in dyslipidemia prevalence from normal weight to obesity class III category. Similar findings have been reported before, suggesting higher obesity and dyslipidemia predisposition in female diabetics -4.6 times higher general obesity and 8 times higher central obesity than males (Anari et al., 2016). However, despite positive association between obesity and diabetes along with contributory effects of hypertension and dyslipidemia in aggravating diabetic complications and treatment intricacies, not a single study has been reported from Pakistan describing association of hypertension and dyslipidemia in obese diabetics and plausible treatment options.

\section{Limitations}

Our study has number of limitations due to observational design of the study, therefore, many demographic variables, such as education, occupation and financial status cannot be examined in predicting their roles in hypertension and dyslipidemia prevalence in obese diabetics over a period of time. Similarly, data cannot be extracted to know that which pathological condition 
developed first and the impact of exposure duration of a particular risk/concomitant disease, e.g., hypertension, leads to another. Moreover, patient's associated factors such as sedentary life style, dietary habits were not estimated in defining the association of these pathological conditions in obese diabetics. Similarly, we are unable to estimate the associations based on general and abdominal adiposity, since visceral adiposity is now considered a major contributor in the development of hypertension, insulin resistance, diabetes and dyslipidemia rather than BMI (Colditz et al., 1995).

\section{CONCLUSION}

In conclusion, hypertension is strongly associated with obesity in diabetics, having higher likelihood of hypertension that increases with increasing weight and obesity class. However, the chances of dyslipidemia became vivid in obese diabetics, predominantly in obesity class III. However, an association of hypertension and dyslipidemia in obese diabetics might warrant a specific treatment or self-care and management practices, because of heterogeneity of multifaceted risks, severity and duration of risk exposure, further complicating the unclear etiology of diabetes co-existed with hypertension, dyslipidemia and obesity. Therefore, further studies are required to determine the unsettled risks, genetic and environmental (stress), and duration of exposure of these risks in bolstering overt clinical manifestations of associated conditions, hypertension, obesity and dyslipidemia in diabetics. Moreover, it would be pertinent to assess that which co-existed condition develops first in diabetics that might initiate or encourage the development of another associated condition and which therapeutic and non-pharmacological management approach at this critical juncture would be the most suitable option to prevent the co-existence of another associated condition.

\section{DECLARATION OF CONFLICTING INTERESTS}

Authors declared no conflict of interests.

\section{FUNDING}

This research did not receive any specific grant or funds from the public, commercial or not-for-profit funding agencies.

\section{REFERENCES}

AdLer AI, Stratton IM, Neil HAW, Yudkin JS, Matthews DR, Cull CA, et al. Association of systolic blood pressure with macrovascular and microvascular complications of type 2 diabetes (UKPDS 36): prospective observational study. BMJ. 2000;321(7258):412-419.

Amos AF, McCarty DJ, Zimmet P. The rising global burden of diabetes and its complications: estimates and projections to the year 2010. Diabetic Med. 1997;14(S5):S7-S85.

Anari R, Amani R, Latifi SM, Veissi M, Shahbazian H. Association of obesity with hypertension and dyslipidemia in type 2 diabetes mellitus subjects. Diabetes Metabolic Syndr Clinl Res Rev. 2017;11(1):37-41.

Association AD. Standards of medical care in diabetes-2015 abridged for primary care providers. Clin Diabetes 2015;33(2):97-111.

Association WM. Declaration of Helsinki. Ethical principles for medical research involving human subjects. 2009.

Berry C, Tardif JC, Bourassa MG. Coronary heart disease in patients with diabetes: part I: recent advances in prevention and noninvasive management. J Am Coll Cardiol. 2007;49(6):631642.

Carr MC, Brunzell JD. Abdominal obesity and dyslipidemia in the metabolic syndrome: importance of type 2 diabetes and familial combined hyperlipidemia in coronary artery disease risk. J Clin Endocrinol Metabol. 2004;89(6):2601-2607.

Chobanian AV, Bakris GL, Black HR, Cushman WC, Green LA, Izzo JL, et al. Seventh report of the joint national committee on prevention, detection, evaluation, and treatment of high blood pressure. Hypertension. 2003;42(6):1206-1252.

Colditz GA, Willett WC, Rotnitzky A, Manson JE. Weight gain as a risk factor for clinical diabetes mellitus in women. Ann Internal Med. 1995;122(7):481-486.

Colosia AD, Palencia R, Khan S. Prevalence of hypertension and obesity in patients with type 2 diabetes mellitus in observational studies: a systematic literature review. Diabetes Metab Syndr Obes. 2013;6(1):327-338. 
Fong DS, Aiello L, Gardner TW, King GL, Blankenship G, Cavallerano JD, et al. Retinopathy in diabetes. Diabetes Care. 2014;27(Suppl 1):s84-s87.

Franssen R, Monajemi H, Stroes ES, Kastelein JJ. Obesity and dyslipidemia. Med Clin North Am. 2011;95(5):893-902.

Gomis R, Artola S, Conthe P, Vidal J, Casamor R, Font B. [Prevalence of type 2 diabetes mellitus in overweight or obese outpatients in Spain. OBEDIA Study]. Med Clin. 2014;142(11):485-492.

Hozumi J, Sumitani M, Matsubayashi Y, Abe H, Oshima Y, Chikuda H, et al. Relationship between neuropathic pain and obesity. Pain Res Manag. 2016;2016:2487924.

Initiative NOE, Heart N, Institute B, Obesity, NAASO, Identification, EP, Overweight, T, Adults Oi. The practical guide: identification, evaluation, and treatment of overweight and obesity in adults. National Heart, Lung, and Blood Institute; 2002.

Kennel W, McGee D. Diabetes and glucose tolerance as risk factors for cardiovascular diseases. The Farmington study. Diabetes Care. 1979;2(2):120-126.

LeRoith D. Hyperglycemia, hypertension, and dyslipidemia in type 2 diabetes mellitus: goals for diabetes management. Clin Cornerstone. 2008;9(Suppl 2):S8-S16.

Nguyen NT, Magno CP, Lane KT, Hinojosa MW, Lane JS. Association of hypertension, diabetes, dyslipidemia, and metabolic syndrome with obesity: findings from the National Health and Nutrition Examination Survey, 1999 to 2004. J Am Coll Surg. 2008;207(6):928-934.

Patel SA, Ali MK, Alam D, Yan LL, Levitt NS, Bernabe-Ortiz $\mathrm{A}$, et al. Obesity and its relation with diabetes and hypertension: a cross-sectional study across 4 geographical regions. Global Heart. 2016;11(1):71-79.

Prabodh S, Sripad DV, Chowdary N, Shekhar R. Hypertension and dyslipidemia in type 2 diabetes mellitus patients of guntur and krishna districts in andhra pradesh, India. Nat J Lab Med. 2012;1(1):7-10.
Qidwai W, Ashfaq T. Imminent epidemic of diabetes mellitus in Pakistan: Issues and challenges for health care providers. J Liaquat Univ Med Health Sci. 2010;9(3):112-113.

Rubin RJ, Altman WM, Mendelson DN. Health care expenditures for people with diabetes mellitus, 1992. J Clin Endocrinol Metabol. 1994;78(4):809A-809F.

Sheth J, Shah A, Sheth F, Trivedi S, Nabar N, Shah N, et al. The association of dyslipidemia and obesity with glycated hemoglobin. Clin Diabetes Endocrinol. 2015;1(1):1-7.

Song S, Hardisty C. Type 2 diabetes mellitus: a high-risk condition for cardiovascular disease irrespective of the different degrees of obesity. QJM. 2008;101(11):875-879.

Turner R, Holman R, Matthews D, Bassett P, Coster R, Stratton I, et al. Hypertension in diabetes study (Hds). Prevalence of hypertension in newly presenting Type-2 diabetic-patients and the association with risk-factors for cardiovascular and diabetic complications. J Hypertens. 1993;11(3):309-317.

Whiting DR, Guariguata L, Weil C, Shaw J. IDF diabetes atlas: global estimates of the prevalence of diabetes for 2011 and 2030. Diabetes Res Clin Pract. 2011;94(3):311-321.

Wild S, Roglic G, Green A, Sicree R, King H. Global prevalence of diabetes estimates for the year 2000 and projections for 2030 . Diabetes Care. 2004;27(5):1047-1053.

Wong TY, Mitchell P. Hypertensive retinopathy. New England J Med. 2004;351(22):2310-2317.

Yoshino G, Hirano T, Kazumi T. Dyslipidemia in diabetes mellitus. Diabetes Res Clin Pract. 1996;33(1):1-14.

Yusuf S, Reddy S, Ôunuu S, Anand S. Global burden of cardiovascular diseases part I: general considerations, the epidemiologic transition, risk factors, and impact of urbanization. Circulation. 2011;104(22):2746-2753.

Received for publication on $21^{\text {st }}$ February 2018 Accepted for publication on $27^{\text {th }}$ June 2018 